\title{
Lusi mud eruption triggered by geometric focusing of seismic waves
}

\author{
M. Lupi, E. H. Saenger, F. Fuchs and S. A. Miller
}

Nature Geoscience 6, 642-646 (2013); published online 21 July 2013; corrected after print 28 August 2014.

In our 2013 article ${ }^{1}$, we adopted a published velocity profile ${ }^{2}$ described as check-shot data, which we used as an input constraint for our numerical simulations. We were subsequently alerted to artefacts in that velocity profile, so below we present revised simulation results, based on additional data.

The seismic P-wave $\left(V_{\mathrm{p}}\right)$ and S-wave $\left(V_{\mathrm{s}}\right)$ velocity profiles measured in the BJP1 borehole (Supplementary Fig. 1) show that the $V_{\mathrm{p}}$ profile extends from a depth of about $300 \mathrm{~m}$ to the bottom of the section. The S-wave and density profiles, however, were only determined from the depth of the casing (approximately $1,100 \mathrm{~m}$ ) to the bottom of the section. As we mentioned previously ${ }^{1}$, the system responds more vigorously to $\mathrm{S}$-wave energy, but the critical information about the $\mathrm{S}$-wave mechanical impedance $\left(V_{\mathrm{s}}\right.$ multiplied by density, $\rho$ ) does not exist for the first 1,100 $\mathrm{m}$ of this section. Instead, we estimate an S-impedance profile above the mud layer by using the observed $V_{\mathrm{p}}$ profile and the observation that $V_{\mathrm{s}}$ in the mud layer is as low as $380 \mathrm{~m} \mathrm{~s}^{-1}$ at $1,100 \mathrm{~m}$ depth. This extremely low value reinforces what has been pointed out elsewhere ${ }^{2,3}$, that the mud layer is a low-velocity zone representative of an over-pressured and under-consolidated sedimentary horizon. Such horizons are common throughout sedimentary basins in Southeast Asia.

We estimate $V_{\mathrm{s}}$ above the mud layer using experimental data (Supplementary Fig. 2) showing the relationship between $V_{\mathrm{s}}$ and $V_{\mathrm{p}}$ at low effective stress ${ }^{4}$. Although the $V_{\mathrm{p}}$ profile above the mud layer seems not to vary significantly (Supplementary Fig. 1a), a closer inspection (Supplementary Fig. 1b) shows that the $V_{\mathrm{p}}$ steadily increases just above the mud layer from about 1,500 $\mathrm{m} \mathrm{s}^{-1}$ to about 2,000 m s $\mathrm{s}^{-1}$, between about 700 and $875 \mathrm{~m}$ depth. The steady increase in $V_{\mathrm{p}}$ with depth, typical of a normal compacting horizon, indicates lower fluid pressures relative to the fluid pressure in the underlying mud layer. We assume that the top of the mud layer corresponds to the observed drop in $V_{\mathrm{p}}$ at around $900 \mathrm{~m}$ depth, which is consistent with the well log data (Supplementary Fig. 3). Using the recorded $V_{\mathrm{p}}$ constraint of 2,000 $\mathrm{m} \mathrm{s}^{-1}$ with a $V_{\mathrm{p}} / V_{\mathrm{s}}$ ratio of about 2.7 (Supplementary Fig. 2), we estimate $V_{\mathrm{s}}$ at the top boundary of the mud layer to be about $750 \mathrm{~m} \mathrm{~s}^{-1}$. We assume that the $380 \mathrm{~m} \mathrm{~s}^{-1} V_{s}$ recorded at $1,100 \mathrm{~m}$ depth extends to the top of the mud layer because of the relatively constant and reduced $V_{\mathrm{p}}$ below the compacting layer (Supplementary Fig. 1b). It should be emphasized that there is considerable uncertainty in $V_{\mathrm{s}}$ above the mud layer, but the observed reduction in $V_{\mathrm{p}}$ with depth (after a systematic increase of velocity with depth in the layer above) corresponds to a far greater reduction in $V_{s}$ within the mud layer. Therefore, the interface between the mud layer and the compacting layer corresponds to an impedance contrast. This is evident in the elevated $V_{\mathrm{p}} / V_{\mathrm{s}}$ ratios of about 4.5 within the mud layer (Supplementary Fig. 4), which again indicate low effective normal stress (Supplementary Fig. 2). At low effective stress, $V_{\mathrm{p}}$ and $V_{\mathrm{s}}$ are only weakly coupled whereby $V_{\mathrm{p}}$ remains relatively constant while $V_{\mathrm{s}}$ varies depending on the pore pressure. The effective stress dependence on $V_{\mathrm{p}} / V_{\mathrm{s}}$ ratios occurs because $V_{\mathrm{s}}$ is solely dependent on the shear modulus while $V_{\mathrm{p}}$ is dominated by the bulk modulus. Since shear modulus varies strongly as a function of pore pressure, small changes in pore pressure at low effective stress generate large changes in $V_{s}$, with little influence on $V_{\mathrm{p}}$. From the available experimental data (Supplementary Fig. 2), we can expect about a factor of two difference in $V_{\mathrm{p}} / V_{\mathrm{s}}$. Although the data ${ }^{4}$ in Supplementary Fig. 2 are from a different lithology than that at Lusi, the physics is lithology-independent.

We multiply our estimated $V_{\mathrm{s}}$ profile (Fig. 1a) with the measured density profile (see Supplementary Fig. 3 ), using $1,800 \mathrm{~kg} \mathrm{~m} \mathrm{~m}^{-3}$ where there is no data, to generate a new impedance profile (Fig. 1b). We used this impedance profile as input for our numerical simulation, using the same input and boundary conditions as described previously ${ }^{1}$. For simplicity, the modelled faults in the previous simulations have been removed.

The results from our revised simulations (Fig. 1c) show that our estimated impedance-contrast between the low-velocity mud layer and the compacting sediments above produces a comparable focusing effect and maximum shear strain, as we reported previously ${ }^{1}$. Notably, our two-dimensional simulations underestimate by a factor of five the additional amplification when the third dimension of this parabolic structure is considered ${ }^{5}$.

Our conclusions ${ }^{1}$ therefore remain unchanged. We appreciate this opportunity to correct the record.

\section{References}

1. Lupi, M., Saenger, E. H., Fuchs, F. \& Miller, S. A. Lusi mud eruption triggered by geometric focusing of seismic waves. Nature Geosci. 6, 642-646 (2013).

2. Istadi, B. P., Pramono, G. H., Sumintadireja, P. \& Alam, S. Modeling study of growth and potential geohazard for LUSI mud volcano: East Java, Indonesia. Mar. Petrol. Geol. 26, 1724-1739 (2009).

3. Tanikawa, W., Sakaguchi, M., Wibowo, H. T., Shimamoto, T. \& Tadai, O. Fluid transport properties and estimation of overpressure at the LUSI mud volcano, East Java Basin. Engin. Geol. 116, 73-85 (2010).

4. Lee, M. W. Predicting S-Wave Velocities for Unconsolidated Sediments at Low Effective Pressure (USGS Scientific Investigations report 2010-5138, 2010).

5. Davis, P. Triggered mud eruption? Nature Geosci. 6, 592-593 (2013).

\section{Acknowledgements}

We thank Maxwell Rudolph at Portland State University, USA, Mark Tingay at the University of Adelaide, Australia, Michael Manga and Chi-Yuen Wang at the University of California, Berkeley, USA, and Richard Davies at Durham University, UK, for alerting us to the errors in the original seismic velocity profile and for providing us with the additional data from the BJP1 borehole.

\section{Additional information}

Supplementary information is available in the online version of the paper. 
a

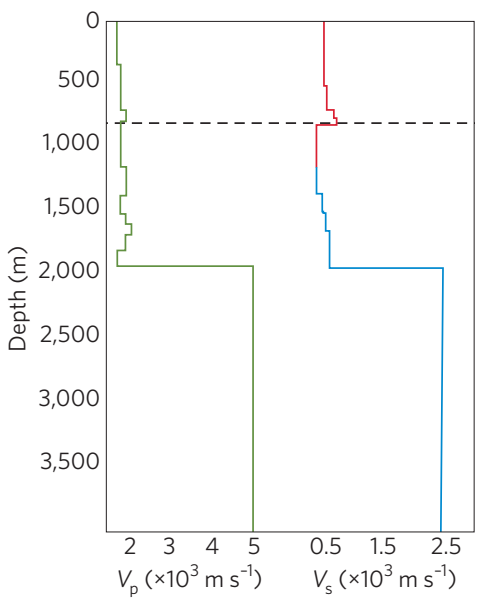

\section{b}

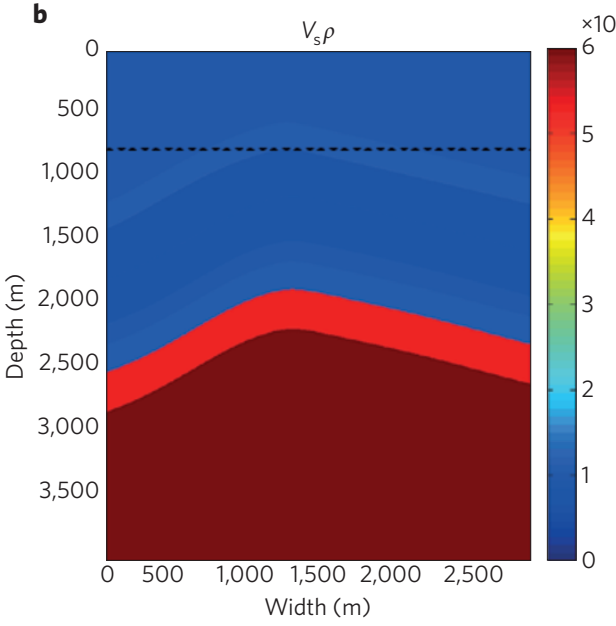

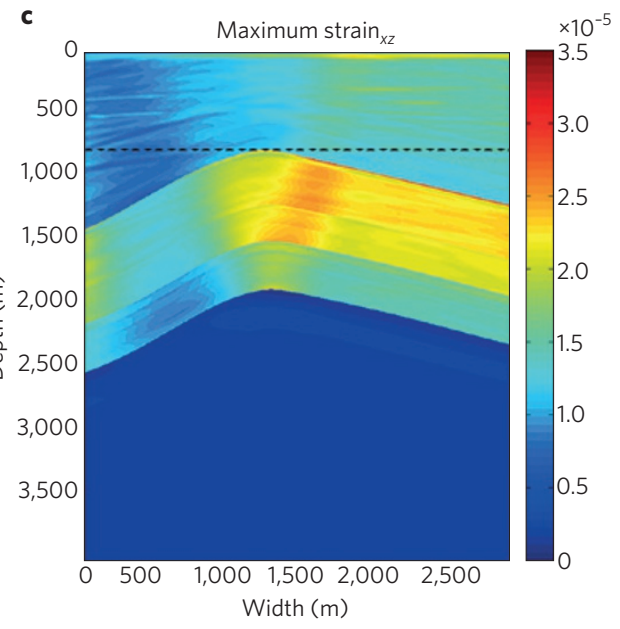

Figure 1 | Revised numerical simulations. a, We estimate a $V_{s}$ (red line) profile based on the measured $V_{p}$ (green line) and $V_{s}(b l u e ~ l i n e)$ profiles. The model domain was discretized into 21 layers (with higher resolution for the first 2,000 m) approximated from the measured and estimated profiles (Supplementary Figs 1 and 2). Experimental data ${ }^{4}$ suggest that $V_{s}$ varies indirectly with $V_{p}$. That is, $V_{p} \propto A V_{s}$ where $A$ is a coefficient that varies depending on the shear modulus, pore pressure and effective pressure (Supplementary Fig. 2). Hence $V_{s}$ does not always correlate positively with $V_{p}$. The observation of $V_{p}=2,000 \mathrm{~m} \mathrm{~s}^{-1}$ directly above the mud layer (Supplementary Fig. 1b) implies from Supplementary Fig. 2 that $V_{\mathrm{s}}=750 \mathrm{~m} \mathrm{~s}{ }^{-1}$, while further observations of $V_{p}=1,600-1,750 \mathrm{~m} \mathrm{~s}^{-1}$ in the mud layer are also consistent with the observation of $V_{s}=380 \mathrm{~m} \mathrm{~s}^{-1}$ and $V_{p} / V_{s}=4.5$ in the mud layer (Supplementary Fig. 4). Therefore, we suggest there is little uncertainty in the magnitude of the impedance contrast, and small changes in these values will not significantly affect our results because they scale with impedance contrast. $\mathbf{b}$, We use the S-wave estimates (a) to construct an S-wave impedance profile (with units $\mathrm{kg} \mathrm{m}^{-2} \mathrm{~s}^{-1}$ ). $\mathbf{c}$, We use the S-wave impedance profile (b) in our numerical simulation, using the same input and boundary conditions as our original model simulation'. The dashed line marks the top of the mud layer. The results from this simulation show that the inferred impedance contrast at Lusi is sufficient to focus seismic energy into the mud layer. 